\author{
Military Technical College \\ Kobry El-Kobbah, \\ Cairo, Egypt.
}

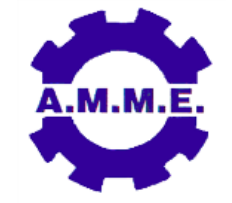

\title{
MODELING AND ANALYSIS OF EXTRUSION PROCESS, PRODUCT AND TOOLING: ESTIMATION AND PREDICTION OF DIE LIFE
}

\author{
Sayyad Z. Qamar ${ }^{1}$
}

\begin{abstract}
Aluminum extrusion finds extensive application in the construction, automobile and aerospace industries. A comprehensive investigation of the entire operation can be divided into three distinct yet inter-related areas: deformation process, dies and tooling, and product defects. Major work in this area has been done by the author and a small group of co-researchers. One major study (Extrusion Process) is an investigation into the variation of extrusion pressure and how it is affected by different process parameters, relationship between extrusion pressure and profile complexity, and interaction of various extrusion parameters in the deformation chamber. In another main study (Extrusion Tooling), the modes and mechanisms of die failure are examined, probabilistic study of die life is undertaken, complexity-based die-life prediction scheme is formulated, fracture toughness evaluation of extrusion die materials is carried out in order to develop an optimum heat treatment strategy, and simulation schemes are worked out to forecast die failures due to fracture and wear. The third principal study (Product Defects) covers defect morphology, defect mechanisms and causes, and remedial measures for various defects encountered in aluminum extrusion, along with statistical analysis of product defects in typical largesize aluminum extrusion plants. First part of the current paper gives an overview of different studies on the process, tooling, and product defects in aluminum extrusion carried out at Sultan Qaboos University and King Fahd University of Petroleum and Minerals, in collaboration with various commercial extrusion plants in the region. Second part of the paper focuses on one of the most important aspects of metal extrusion: estimation and prediction of service life of dies and related tooling. Using the Monte Carlo simulation technique, a fracture mechanics based fatigue life prediction model is first presented. A similar treatment is then described for wear-related failures. A simplified approach of plate-with-edge-crack is initially used to develop a fatigue life prediction model for tube dies. Extrusion die is later modeled as a pressurized-cylinderwith-internal-crack, a more realistic approach for a hollow (tube) die. Sensitivity analysis is then carried out to evaluate the dependence of fracture life of hollow extrusion dies on material and process parameters.
\end{abstract}

1 Mechanical and Industrial Engineering Department, Sultan Qaboos Univ., AlKhoudh, Muscat, Sultanate of Oman; sayyad@squ.edu.om. 